\title{
Preparation of crosslinked $\beta$-cyclodextrin polymer beads and their application as a sorbent for removal of phenol from wastewater
}

\author{
Hirohito Yamasaki, ${ }^{1 *}$ Yousuke Makihata $^{1}$ and Kimitoshi Fukunaga ${ }^{2}$ \\ ${ }^{1}$ Department of Chemical and Biological Engineering, Ube National College \\ of Technology, 2-14-1 Tokiwadai, Ube, Yamaguchi 755-8555, Japan \\ 2 Department of Sustainable Engineering (Chemistry), Graduate School of \\ Science and Engineering, Yamaguchi University, 2-16-1 Tokiwadai, Ube, \\ Yamaguchi 755-8611, Japan
}

\begin{abstract}
BACKGROUND: Phenols are commonly encountered in aqueous effluents from various manufacturing processes such as oil refineries, coke plants, and phenolic resin plants, and are toxic substances that should be removed from the aquatic environment. We describe the preparation of beaded crosslinked $\beta$-CyD polymers, and the removal of phenol from raw industrial wastewater discarded from phenolic resin processing by the obtained $\beta$-CyD adsorbent.
\end{abstract}

RESULTS: The crosslinked $\beta$-CyD prepolymer was synthesized by treatment of $\beta$ CyD with hexamethylene diisocyanate (HDI) at a molar ratio of 1:8. The suspension of the resulting powdery prepolymer in aqueous sodium alginate was added dropwise into an aqueous calcium chloride solution to precipitate the spherical $\beta$-CyD prepolymer gels. The spherical prepolymer gel was lyophilized and re-crosslinked with HDI to afford the $\beta$-CyD polymer beads. The physical properties of the beads were as follows: average diameter: $3.4 \mathrm{~mm}$; average compressive strength: $2.17 \mathrm{M} \mathrm{Pa}$; porosity: $47.0 \%$; specific surface area: $3.48 \mathrm{~m}^{2} / \mathrm{g}$. The removal of phenol from raw industrial phenolic wastewater with the $\beta$-CyD polymer beads was carried out in either a shaker or upflow column at $25^{\circ} \mathrm{C}$. After seven times of accumulated adsorption, the phenol concentration of $89000 \mathrm{ppm}$ decreased to as low as $350 \mathrm{ppm}$ in the former and $490 \mathrm{ppm}$ in the latter.

CONCLUSION: Adsorbent [ $\beta$-CyD/HDI(1/8)]/HDI polymer beads having a good regular shape and high mechanical stabilities were newly prepared by a stepwise crosslinked method. The results of sorption experiments show that the beads exhibit high sorption capacities toward phenolics in raw industrial wastewater.

Keywords: $\beta$-cyclodextrin; phenol removal; polymer beads; diisocyanate network polymer; raw industrial wastewater

\footnotetext{
*Correspondence to: Hirohito Yamasaki, Department of Chemical and Biological Engineering, Ube National College of Technology, 2-14-1 Tokiwadai, Ube, Yamaguchi 755-8555, Japan

E-mail: yamasaki@ube-k.ac.jp
} 
Contract/grant sponsor: The Ministry of Education, Culture, Sports, Science and Technology, Japan; contract/grant number: 15710069, and The Conference for Reduction of Energy \& Heat-trapping Gas in The Ube Industrial Complex. 


\section{INTRODUCTION}

Phenols (phenol and phenolic compounds) are commonly encountered in aqueous effluents from various manufacturing processes such as oil refineries, coke plants, and phenolic resin plants, and are toxic substances that should be removed from the aquatic environment. In our research in a recent article, ${ }^{1,2}$ we carried out an attempt to find a novel cyclodextrin (CyD) polymer for the removal of phenols from raw industrial wastewater discarded from phenolic resin processing, and found that the most efficient removal method was by pulverized crosslinked $\beta$-CyD with hexamethylene diisocyanate (HDI) in a 1:8 molar ratio, or pulverized crosslinked Mix-CyD ( $\alpha$-CyD: $\beta$-CyD: $\gamma$-CyD: dextrin = $30: 10: 10: 50 \mathrm{wt} / \mathrm{wt}$ ) with HDI, also in a 1:8 molar ratio, with a mean diameter of below $53 \mu \mathrm{m}$. However, the types of equipment that can be employed for the removal of pollutants from water are the stirred-tank, fluidized bed, and column. Therefore, the use of adsorbents of largeparticle size is advantageous in that the adsorbents can be easily separated from the medium for the purpose of recycling or controlling the removal progress. In this paper, we describe the preparation of beaded crosslinked $\beta$-CyD polymers using a stepwise crosslinked method, and the removal of phenol from raw industrial wastewater discarded from phenolic resin processing by the obtained $\beta$-CyD adsorbent.

\section{MATERIALS AND METHODS Experimental apparatus and procedures}

\section{Reagents}

$\beta$-CyD was kindly supplied by Mercian Co., Ltd. (Tokyo) and used without further purification. Sodium alginate (Na Alg.) was purchased from Sigma-Aldrich Japan (Tokyo). Hexamethylene diisocyanate (HDI), dibutyltin dilaurate (BTL), and $N, N$ dimethylformamide (DMF) were purchased from Tokyo Kasei Kogyo (Tokyo), and HDI, DMF and benzene were purified by distillation. All other organic and inorganic reagents were of the purest grade and available from commercial sources.

\section{Preparation of spherical porous crosslinked $\beta$-CyD polymers}

The spherical crosslinked $\beta$-CyD polymers were prepared. The methods are the same; only pre-polymer differs, as described in Chart 1 . $\beta$-CyD prepolymers of low and high crosslinkage were synthesized by treatment of $\beta$-CyD with HDI at a molar ratio of $1: 2$ and 1:8 (mol/mol), respectively. ${ }^{1,2}$ Pasty prepolymers were obtained by the former protocol, and the number-average molecular weight and degree of polymerization were determined to be about $1.12 \times 10^{4}$ and 9.6 by mass spectrometry, using a MALDI-TOF/MS Voyager-DE ${ }^{\mathrm{TM}}$ PRO (Applied Biosystems Japan, Tokyo). On the other hand, powdery prepolymers were obtained by the latter protocol. Solid prepolymers were ground by ball-milling to give fine particles with a mean diameter of below $53 \mu \mathrm{m}$, as previously described. ${ }^{1,2}$

The suspension of either prepolymers in $1 \mathrm{wt} \%$ of aqueous Na Alg. solution (50 - 60 wt\%) was added dropwise into an aqueous calcium chloride solution (3 wt\%) to precipitate the spherical crosslinked $\beta$-CyD prepolymers. Then, the resulting spherical prepolymers were followed by lyophilization (used freezer at $-20^{\circ} \mathrm{C}$ ), re-crosslinked with HDI (Prepolymers/HDI = 1/1.5 (wt/wt)) in benzene for $24 \mathrm{~h}$ at $80^{\circ} \mathrm{C}$, and washed with chloroform and methanol $(\mathrm{MeOH})$. After drying at $60^{\circ} \mathrm{C}$ in vacuo, the crosslinked $\beta$-CyD polymers were used as a sorbent for the removal of phenol.

The $\beta$-CyD contents of the prepared sorbents were estimated by elemental composition, determined by a CHN elemental analyzer 2400 II (Perkin Elmer Japan 
Co. Ltd., Yokohama). The compressive strength area, the specific surface area, and the porous volume of the adsorbents were determined by the use of a tensile and compressive testing machine, STA-1150 (A\&D Co. Ltd., Tokyo), a BET ${ }^{3}$ apparatus NOVA-1200 (Yuasa-Ionics Co. Ltd., Osaka), and a Pore Master 60-GT (Yuasa-Ionics Co. Ltd.), respectively. The surface properties of the adsorbents were studied by scanning electron microscopy (SEM) with a FE-SEM S-4300 (Hitachi HighTechnologies Co., Tokyo) using an accelerating voltage of $3 \mathrm{keV}$ after coating with Pt, as well as optical microscopy with a digital microscope, VH-8000 (Keyence Co., Osaka).

\section{Adsorption Experiments}

Equilibrium adsorbent batchwise tests were carried out by placing weighed quantities of the porous $\beta$-CyD beads $(1.0 \mathrm{~g})$ and samples of phenol wastewater solution $\left(5 \mathrm{~cm}^{3}\right)$ in a $50-\mathrm{cm}^{3}$ Erlenmeyer flask sealed by polyethylene film and shaking the flask for a fixed time in a $25^{\circ} \mathrm{C}$ chamber at $80 \mathrm{rpm}$. Aqueous industrial wastewater discharged from phenolic resin processing from Meiwa Plastic Industries, Ltd. (Ube), of which the components were phenol (8.9 wt\%), $m$ - and $p$ - cresols (0.33 wt\%), xylenols (0.044 $w t \%)$, methanol (9.95 wt\%) at $\mathrm{pH}=3.0$, was used in all adsorption experiments. At arbitrary intervals, aliquots $\left(0.1-0.2 \mathrm{~cm}^{3}\right)$ were withdrawn from the solution, and the concentration of phenol was determined with a capillary gas chromatograph fitted with a flame ionization detector (model GC-6APTF; Shimadzu, Kyoto) employing a Silicone-OV-17/Chromosorb WAW DMCS column (GL Science Inc., Tokyo). The lower limit of the detection was $0.005 \mathrm{wt} \%$.

Adsorption tests with experimental apparatus consisting of a continuous upflow column with a volume of $115 \mathrm{~cm}^{3}$ (ID $35 \mathrm{~mm}$; height $120 \mathrm{~mm}$ ) were also carried out (Fig. 1). Twenty-five grams of adsorbent beads were charged, then $125 \mathrm{~cm}^{3}$ of phenol wastewater solution was supplied to the column and circulated at different liquid velocities for four days. The time-courses of the phenol uptake within 4 days were followed by determination of the concentration of phenol, as well as in the case of the batchwise experiment. All experiments were conducted at $25^{\circ} \mathrm{C}$.

\section{RESULTS AND DISCUSSION \\ Preparation of $\beta$-CyD polymer beads}

The $\beta$-CyD polymer beads thus prepared are designated hereafter as $\beta$ $\mathrm{CyD} / \mathrm{HDI}(n)] / \mathrm{HDI}$, where $n$ refers to the molar ratio of $\mathrm{HDI}$ to $\beta$-CyD in the preparation of the prepolymer.

Table 1 summarizes the physical properties of the adsorbent beads. Adsorbents spherical in shape were observed under a microscope (Fig. 2). The scanning electron microscope (SEM) pictures of transverse- and surface-angles for $[\beta$ CyD/HDI(1/8)]/HDI beads are shown in Fig. 3.

\section{Preliminary experiments on the performance of $\beta$-CyD polymer beads}

The capacity of each $\beta$-CyD polymer bead was determined by its removal efficiency per 1 gram of beads for the uptake of phenol from $5 \mathrm{~cm}^{3}$ of wastewater solution for 2 $\mathrm{h}$ in the batchwise case. The results in Table 2 show that the phenol removal efficiency of the polymer beads, $[\beta-\mathrm{CyD} / \mathrm{HDI}(1 / 8)] / \mathrm{HDI}$, was not as good as fine polymer powder, $\beta$-CyD/HDI(1/8), i.e., prepolymer powder. The beads, however, have higher compressive strength and porosity, and a more regular shape with a diameter of about $3 \mathrm{~mm}$, which is most suitable for industrial purposes (Table 1 and 
Fig. 2). Recent developments in the preparation of adsorbents containing polysaccharides such as CyD and their advantages for the removal of pollutants from wastewater were fully reviewed by Crini. ${ }^{4}$

The molar ratio of the adsorbed phenol into the $\beta$-CyD moiety in the $\beta$-CyD polymer beads was expected to be one or at most two, if the sorption mechanism was solely due to the formation of an inclusion complex between the CyD moiety in the beads and the phenol through host-guest interactions. However, the adsorption behavior of the $[\beta-\mathrm{CyD} / \mathrm{HDI}(1 / 2)] / \mathrm{HDI}$ and $[\beta-\mathrm{CyD} / \mathrm{HDI}(1 / 8)] / \mathrm{HDI}$ cannot be completely described by this mechanism because the molar ratios of the adsorbed phenol onto the $\beta$-CyD polymer beads were 5.5 and 9.5, respectively (Tables 1 and 2). Thus, physical adsorption in the $\beta$-CyD polymer network and chemical interactions via the hydrogen bonding formed with phenol between hydroxyl and/or amide groups were also involved in the present sorption process, as described by Crini and Morcellet. ${ }^{5,6}$ The image for the adsorbed phenol onto the $\beta$-CyD polymer beads by different interactions was illustrated in Fig. 4.

From the $\beta$-CyD residue contents in the polymer beads (in Table 1) and the adsorption results (in Table 2), the phenol sorption capacities for [ $\beta$ $\mathrm{CyD} / \mathrm{HDI}(1 / 2)] / \mathrm{HDI}$, [ $\beta$-CyD/HDI(1/8)]/HDI, and $\beta$-CyD/HDI(1/8) were determined to be $\left.2.79 \mathrm{mmol}^{\text {(g-resin) }}\right)^{-1}, 3.03 \mathrm{mmol}^{\text {(g-resin) }}{ }^{-1}$ and $3.74 \mathrm{mmol}^{\text {(g-resin) }}{ }^{-1}$, respectively. The phenol sorption capacity of $43.4 \mu \mathrm{mol}$ (g-resin) ${ }^{-1}$ or $0.1 \mathrm{mmol}(\mathrm{g}$ resin $)^{-1}$ for the $\beta$-CyD epichlorohydrin crosslinked network polymers have been reported. $^{7,8}$ Thus, this indicates that the present $\beta$-CyD polymer beads remove phenol more effectively than the other $\beta$-CyD network polymers. The $[\beta$-CyD/HDI(1/8)]/HDI beads showed higher adsorption capacities for phenol than for [ $\beta$-CyD/HDI(1/2)]/HDI beads, suggesting that the former sobent has a richer polymer network structure suitable for the sorption process. Regardless of bead size, the adsorption capacities of the $[\beta-\mathrm{CyD} / \mathrm{HDI}(1 / 8)] / \mathrm{HDI}$ beads were comparable to those of the $\beta$-CyD/HDI(1/8) polymer powder. Thus, the polymer beads, $[\beta-\mathrm{CyD} / \mathrm{HDI}(1 / 8)] / \mathrm{HDI}$, were selected as the practical adsorbent beads and solely used in the subsequent experiments.

\section{Performance of $\beta$-CyD polymer beads in batchwise adsorption}

The time-courses of the phenol uptake with 48 [ $\beta$-CyD/HDI(1/8)]/HDI polymer beads (1.0 g) were followed during $6 \mathrm{~h}$ and 4 days (Fig. 5). As can be seen, $53 \%$ of the phenol was removed within $30 \mathrm{~min}$ and $78 \%$ of the phenol was removed at equilibrium after 3 days. With the present $[\beta-\mathrm{CyD} / \mathrm{HDI}(1 / 8)] / \mathrm{HDI}$ polymer beads, a two-stage uptake of phenol was observed, while with $\beta$-CyD/HDI(1/8) polymer powder only almost instantaneous adsorption reaching equilibrium was observed. ${ }^{1,2}$ This behavior seems to be due to both the increase in particle size and the two-layer structures of the polymer beads resulting from the two stages of crosslinking of $\beta$ CyD, as shown in Fig. 3 (A): a hard skin layer (outer layer) of poor permeability and a soft core layer (inner layer) of good permeability.

Next, the removal of phenol with $[\beta-\mathrm{CyD} / \mathrm{HDI}(1 / 8)] / \mathrm{HDI}$ beads in the batchwise case was repeated seven additional times with a resulting supernatant solution (Fig. 6). After seven times of accumulated treatment, the concentration of $8.9 \mathrm{wt} \%$ phenol decreased to as low as $350 \mathrm{ppm}$ from $89000 \mathrm{ppm}$.

\section{Regeneration of the $\beta$-CyD polymer beads}


Regeneration of the $[\beta-\mathrm{CyD} / \mathrm{HDI}(1 / 8)] / \mathrm{HDI}$ sorbent was examined following the method of our previous paper. ${ }^{1,2}$ The adsorbed phenols were removed from the adsorbent conducted by soaking it in $50 \mathrm{~cm}^{3}$ of methanol at $25{ }^{\circ} \mathrm{C}$. After $24 \mathrm{~h}$ the adsorbent was filtered off and dried in vacuo. The results for the removal of phenol using the regenerated $\beta$-CyD beads are summarized in Fig. 7. The adsorbent retained about $96 \%$ of its original phenol uptake ability even after using it five times because the elution of the phenol included in the polymer beads with methanol was easily accomplished quantitatively under mild conditions.

\section{Mechanical stability of the $\beta$-CyD polymer beads in batchwise adsorption}

Visual judgment of the breakup was done for all of the 1205 adsorbent beads ( $25 \mathrm{~g}$ ), classifying them into three categories-- i.e., unchanged, cracked, and broken (split up into some particles). Each batchwise adsorption was carried out by placing all of the regenerated adsorbents $(25 \mathrm{~g})$ and fresh phenol wastewater solution $\left(125 \mathrm{~cm}^{3}\right)$, in a $300-\mathrm{cm}^{3}$ Erlenmeyer flask, and shaking the mix at $80 \mathrm{rpm}$ for 1 day at $25^{\circ} \mathrm{C}$. After regeneration, the weight of the beads that belonged to each category was measured to evaluate the mechanical stability of the adsorbent beads. The experimental results are summarized in Fig. 8. During a 10-day period, only $0.9 \mathrm{wt} \%$ of the beads had cracked. Hence, $\beta$-CyD polymer beads with good physical stability are recommended for practical application of this adsorbent for the removal of phenols from raw industrial wastewater.

\section{Performance of $\beta$-CyD polymer beads in an upflow column}

One thousand two hundred and five $\beta$-CyD polymer beads ( $25 \mathrm{~g}$ ) were placed in the column, then $125 \mathrm{~cm}^{3}$ of phenol wastewater was supplied and circulated at a flow rate of $2.2-19.0 \mathrm{~cm}^{3} / \mathrm{s}$ in order to permit full fluidization of the adsorbent beads. Fig. 9 shows the effects of the phenol wastewater circulation rate on the phenol removal efficiencies in the upflow column and time plots of the batchwise phenol removal. During the enrichment period of soaking phenol for up to $6 \mathrm{~h}$, the phenol removal efficiencies were greatly affected by the flow rate, and reached equilibrium efficiency after 4 days. These results indicate that adsorption with the $\beta$-CyD polymer beads was affected by intra-particle mass transfer limitation, which did not exist in the process with the previous fine $\beta$-CyD polymer powder, ${ }^{1,2}$ due to the increase in particle size, the higher density, and/or the lower porosity of the bulk material.

Finally, the removal of phenol with the $\beta$-CyD polymer beads in the upflow column was repeated seven additional times with the supernatant wastewater solution (Fig. 10). The adsorbent removed the phenol from acidic/phenolic wastewater containing $89000 \mathrm{ppm}$ phenol to a concentration as low as $490 \mathrm{ppm}$, after seven times of accumulated treatment.

\section{CONCLUSION}

Adsorbent [ $\beta$-CyD/HDI(1/8)]/HDI polymer beads having a good regular shape with a diameter of $3 \mathrm{~mm}$ and high mechanical stabilities for the removal of phenols from phenolic industrial wastewater were successfully prepared by a stepwise crosslinked method. The uptake of phenols from phenolic wastewater with the beads attaining equilibrium fairly slowly due to intra-particle mass transfer limitation was in contrast to the case with the fine $\beta$-CyD polymer powder. However, the adsorption employing the present $\beta$-CyD polymer beads was easy to operate and could be achieved by 
various apparatus such as a stirred-tank, packed bed, or fluidized bed (expanded bed).

\section{ACKNOWLEDGEMENTS}

This work was partly supported by a Grant-in-Aid for Young Scientists (B) (No.15710069) from the Ministry of Education, Culture, Sports, Science and Technology Japan (2003-2005), and by a research promotion grant from the Conference for Reduction of Energy \& Heat-trapping Gas in the Ube Industrial Complex (2005-2008). The authors are grateful to Mercian Co., Ltd. (Tokyo) and Meiwa Plastic Industries, Ltd. (Ube) for the provision of RINGDEX-B and the phenolic wastewater, respectively.

\section{REFERENCES}

(1) Yamasaki H, Makihata $\mathrm{Y}$ and Fukunaga K, Efficient phenol removal of wastewater from phenolic resin plants using crosslinked cyclodextrin particles. $J$ Chem Technol Biotechnol 81:1271-1276 (2006).

(2) Yamasaki $\mathrm{H}$, Matsui $\mathrm{H}$ and Fukunaga $\mathrm{K}$, Efficient phenol removal of raw industrial wastewater from phenolic resin plants using crosslinked $\beta$-cyclodextrin adsorbent. Japanese Environ Conser Eng 36:50-56 (2007).

(3) Brunauer S, Emmett P and Teller E, B. E. T. method. J Am Chem Soc 60:309 (1938)

(4) Crini G, Recent developments in polysaccharide-based materials used as adsorbents in wastewater treatment. Prog Polym Sci 30:38-70 (2005).

(5) Crini G, Morcellet M, Synthesis and applications of adsorbents containing cyclodextrins. J Sep Sci 25:789-813 (2002).

(6) Crini G, Janus L, Morcellet M, Torri G, Morin N, Sorption properties toward substituted phenolic derivative in water using macroporous polyamines containing $\beta$-cyclodextrin. J Appl Polym Sci 73:2903-2910 (1999).

(7) Crini G, Bertini S, Torri G, Naggi A, Sforzini D, Vecchi C, Janus L, Lekchiri Y Morcellet $\mathrm{M}$, Sorption of aromatic compounds in water using insoluble cyclodextrin polymers. J Appl Polym Sci 68:1973-1978 (1998).

(8) Kiji J, Konishi H, Okano T, Terashima T. Motomura K, Adsortion of organic species by a cyclodextrin epichlorohydrin network polymer. Angew Macromol Chem 199:207-210 (1992). 


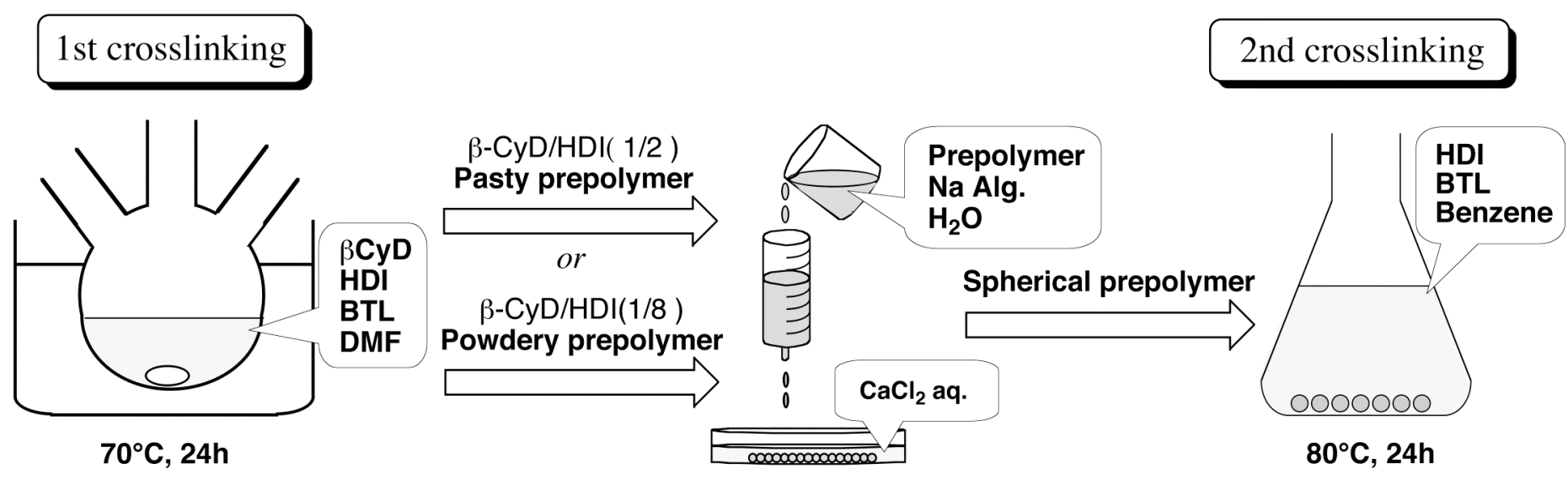

Chart 1 
Table 1. Physical properties of the $\beta$-CyD polymer beads

\begin{tabular}{|c|c|c|c|c|c|c|}
\hline Adsorbent & $\begin{array}{c}\text { Average diameter } \\
(\mathrm{mm})\end{array}$ & $\begin{array}{l}\text { Bulk density }{ }^{a} \\
\qquad\left(\mathrm{~g} / \mathrm{cm}^{3}\right)\end{array}$ & $\begin{array}{l}\text { Porosity }^{a} \\
\text { (\%) }\end{array}$ & $\begin{array}{c}\text { Specific surface area } \\
\qquad\left(\mathrm{m}^{2} / \mathrm{g}\right)\end{array}$ & $\begin{array}{c}\text { Compressive strength } \\
\text { ( } \mathrm{M} \mathrm{Pa})\end{array}$ & $\begin{array}{c}\beta-C y D^{d} \\
(\mu \mathrm{mol} / \mathrm{g})\end{array}$ \\
\hline$[\beta-C y D / H D I(1 / 2)] / H D I$ & 2.7 & 0.76 & 44.2 & 0.75 & 0.98 & 507 \\
\hline$[\beta-C y D / H D I(1 / 8)] / H D I$ & 3.4 & 0.74 & 47.0 & 3.48 & 2.17 & 319 \\
\hline
\end{tabular}

\footnotetext{
a Determined by Pore Master 60-GT.

${ }^{\mathrm{b}}$ Determined by NOVA-1200.

${ }^{\mathrm{c}}$ Determined by STA-1150.

${ }^{\mathrm{d}}$ The content of $\beta$-CyD residue in polymer beads determined by CHN elemental analyzer $2400 \mathrm{II}$.
} 
Table 2. The performance of $\beta-C y D$ polymer beads for phenol adsorption ${ }^{a, b}$

\begin{tabular}{|c|c|c|}
\hline \multirow[t]{2}{*}{ Adsorbent } & $\underline{\text { Separation efficiency }}^{\mathrm{C}}$ & $\underline{\text { Residual conc. of phenol }}$ \\
\hline & $\%$ & wt\% \\
\hline$[\beta-\mathrm{CyD} / \mathrm{HDI}(1 / 2)] / \mathrm{HDI}^{\mathrm{d}}$ & 59 & 3.6 \\
\hline$[\beta-C y D / H D I(1 / 8)] / H D I^{e}$ & 64 & 3.2 \\
\hline$\beta-\mathrm{CyD} / \mathrm{HDI}(1 / 8)^{\dagger}$ & 79 & 1.9 \\
\hline
\end{tabular}

${ }^{a}$ Initial concentration of phenol was $8.90 \mathrm{wt} \%$.

b The adsorption was carried out by placing an adsorbent $(1.0 \mathrm{~g})$ and a wastewater solution $\left(5 \mathrm{~cm}^{3}\right)$ in a $50-\mathrm{cm}^{3}$ Erlenmeyer flask and shaking the flask in a $25^{\circ} \mathrm{C}$ chamber at $80 \mathrm{rpm}$ for $2 \mathrm{~h}$.

c Separation efficiency (\%) was calculated from the difference between the concentrations of phenol before and after adsorption.

d Polymer beads (average diameter of $2.7 \mathrm{~mm}$ ).

e Polymer beads (average diameter of $3.4 \mathrm{~mm}$ ).

f Polymer powders (diameter of below $53 \mu \mathrm{m}$ ). 

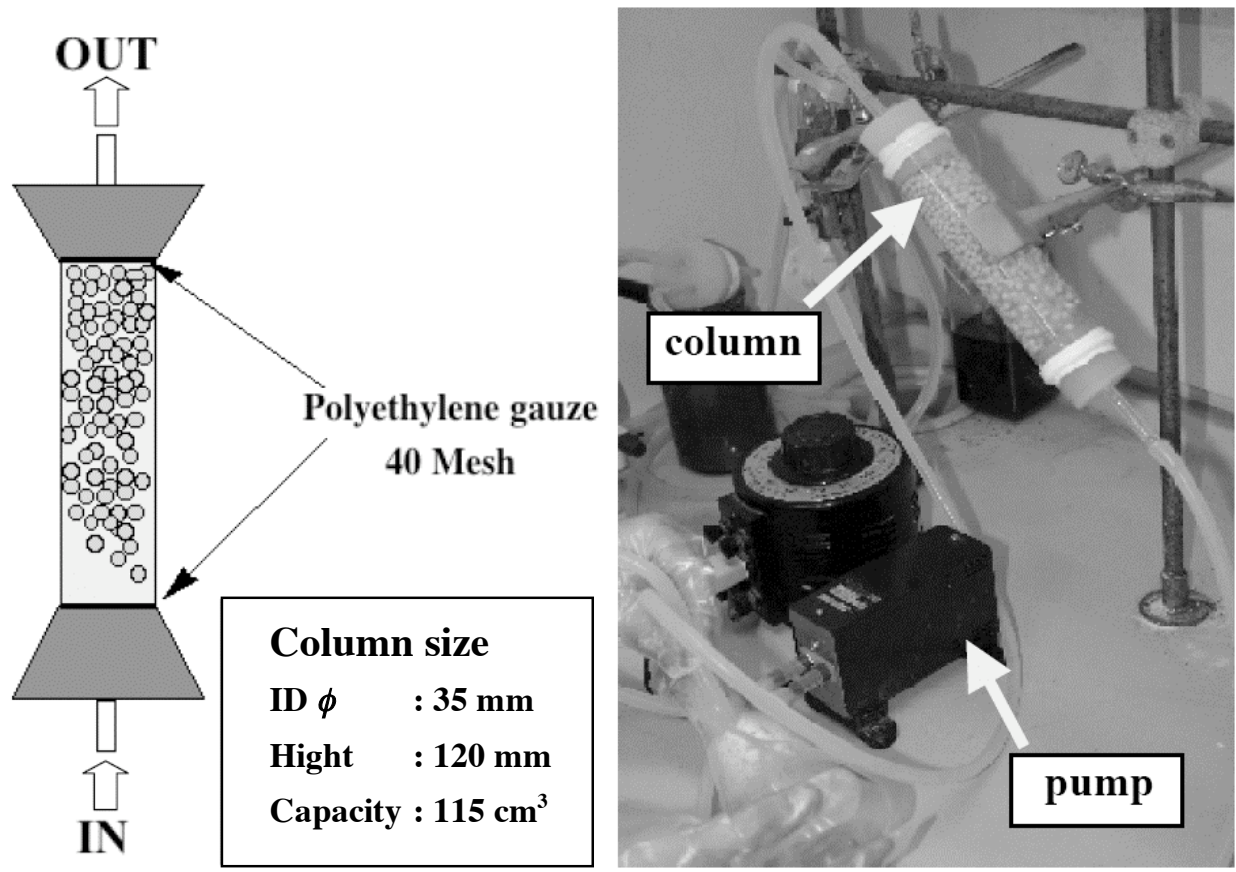

Figure 1. The experimental continuous apparatus. 

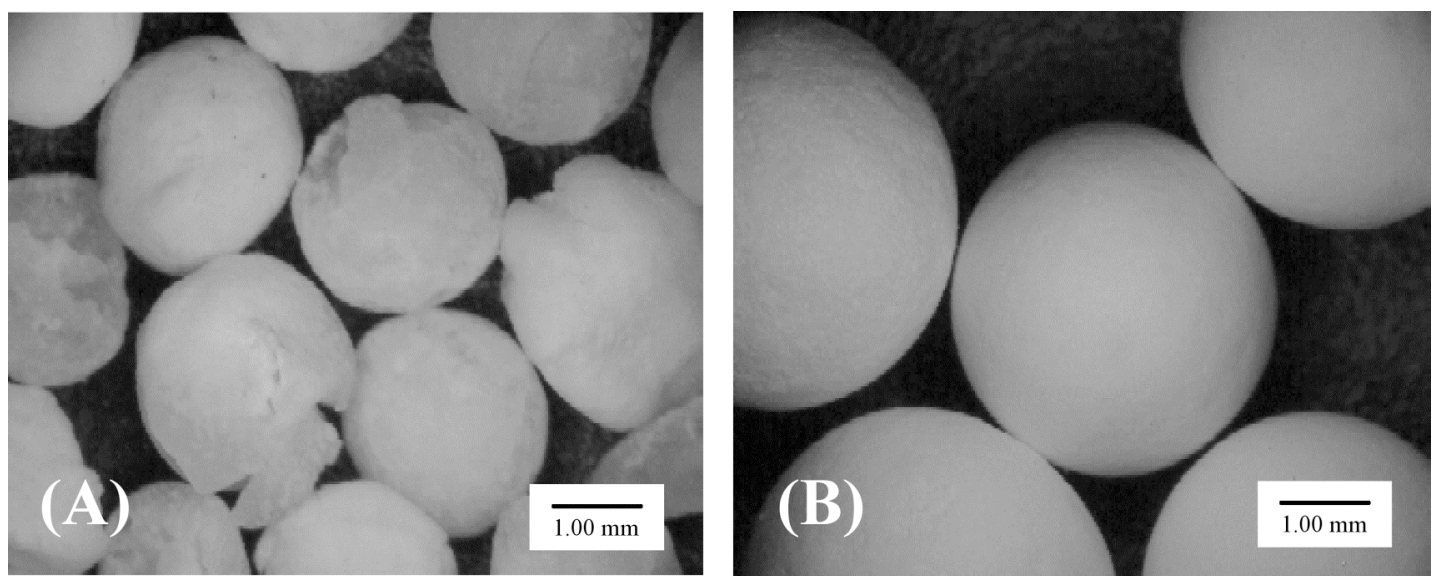

Figure 2. Optical micrograph photograph of $(A)$ Beads from pasty prepolymer, $[\beta-\mathrm{CyD} / \mathrm{HDI}(1 / 2)] / \mathrm{HDI}$ and $(\mathrm{B})$ Beads from powdery prepolymer, $[\beta-\mathrm{CyD} / \mathrm{HDI}(1 / 8)] / \mathrm{HDI}$. 

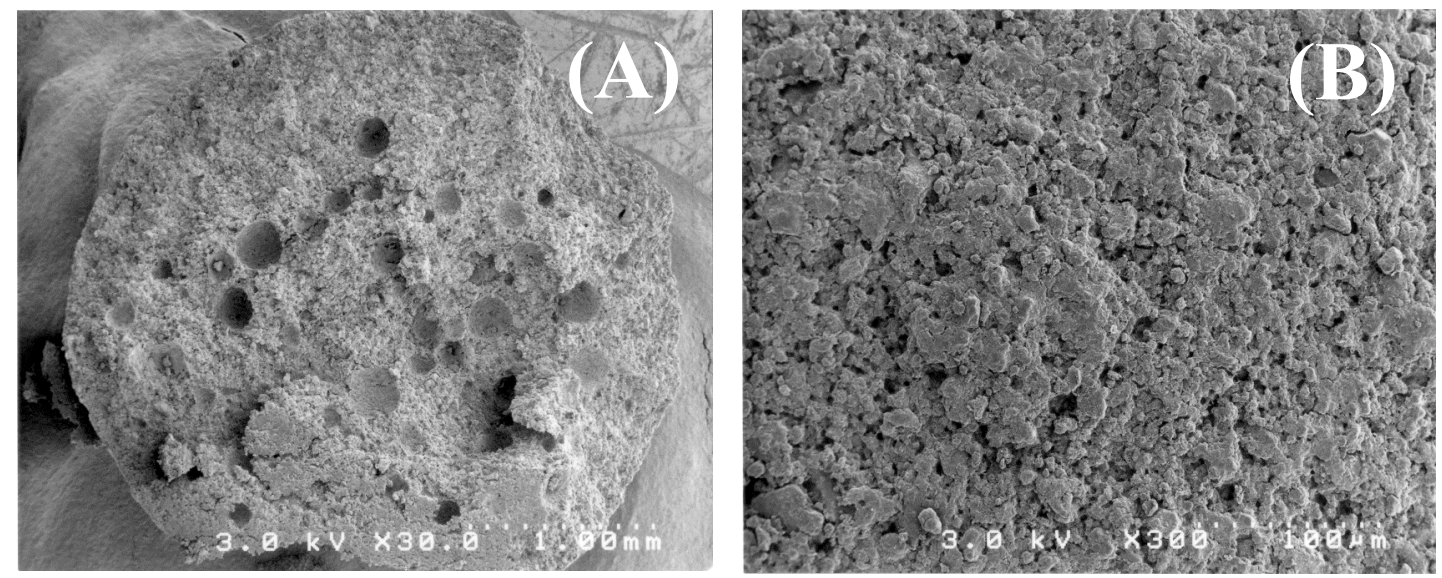

Figure 3. SEM pictures of transverse $(A)$ and surface layer $(B)$ of the $[\beta-\mathrm{CyD} / \mathrm{HDI}(1 / 8)] / \mathrm{HDI}$ bead polymer. 


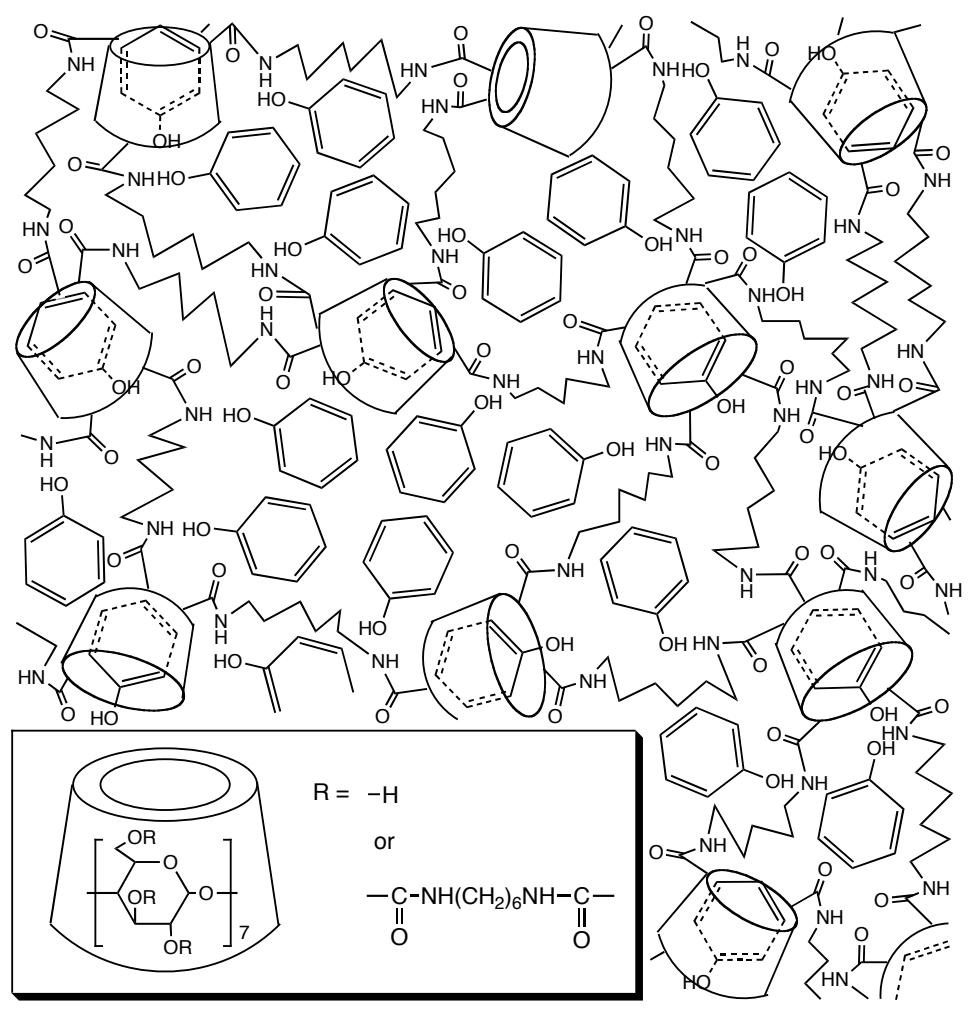

Figure 4. Scheme of the image for the adsorbed phenol onto the $\beta$-CyD polymer beads in aqueous industrial wastewater discharged from phenolic resin processing. 

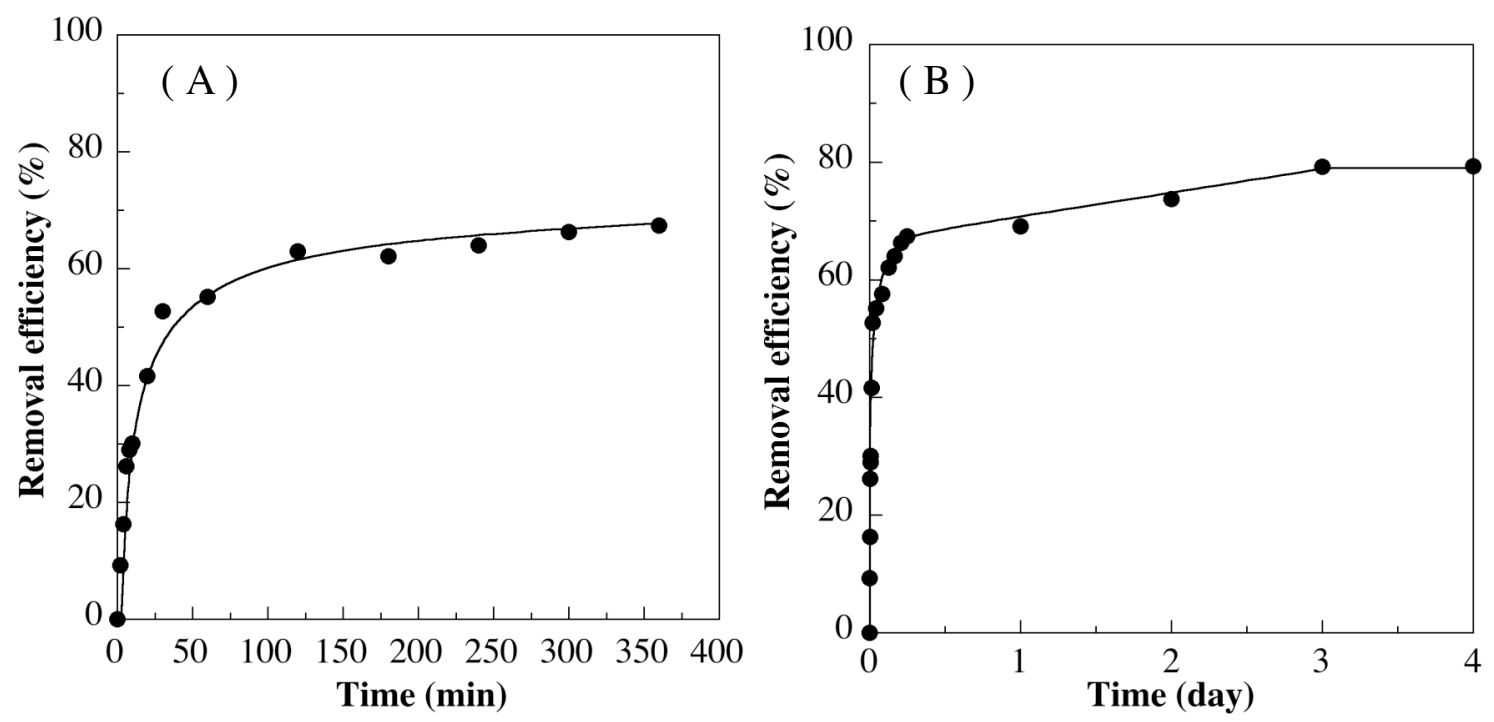

Figure 5. Time plots of the removal of phenol with $[\beta-\mathrm{CyD} / \mathrm{HDI}(1 / 8)] / \mathrm{HDI}$ sorbent $(1.0 \mathrm{~g})$ from phenolic wastewater solution $\left(5 \mathrm{~cm}^{3}\right)$ at $25^{\circ} \mathrm{C}$. (A) for $6 \mathrm{~h},(B)$ for 4 days. 


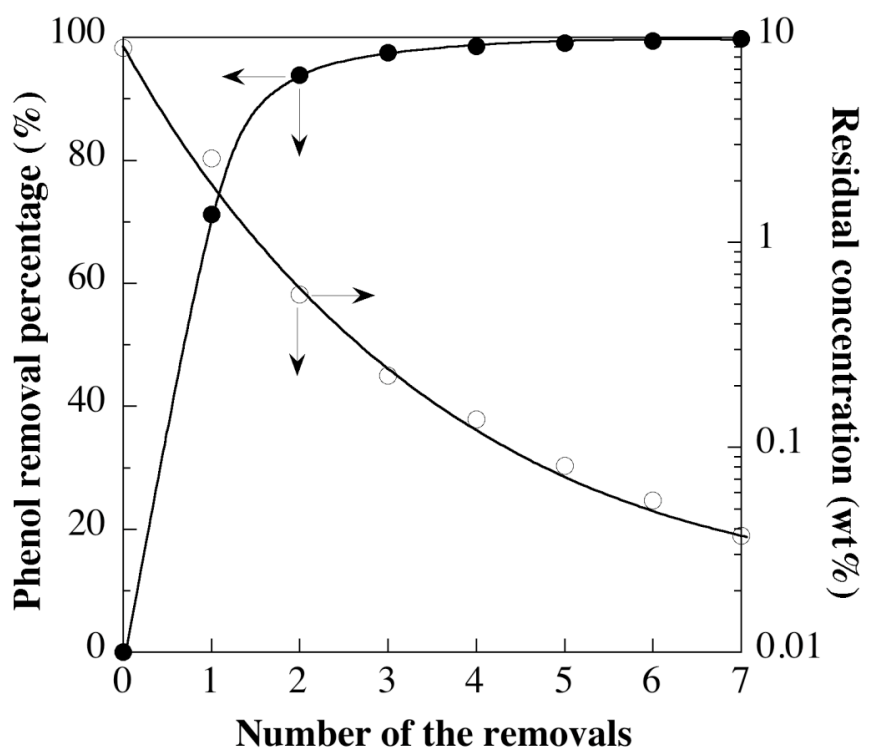

Figure 6. Repetition of the removal of phenol with $[\beta-\mathrm{CyD} / \mathrm{HDI}(1 / 8)] / \mathrm{HDI}$ polymer beads in batchwise adsorption: Each adsorption was carried out by placing a fresh adsorbent $(1.0 \mathrm{~g})$ and wastewater solution $\left(5 \mathrm{~cm}^{3}\right)$, from which the previous adsorbents were filtered off, in a $50-\mathrm{cm}^{3}$ Erlenmeyer flask and shaking it at $25^{\circ} \mathrm{C}$ in a chamber at $80 \mathrm{rpm}$ for 1 day. 


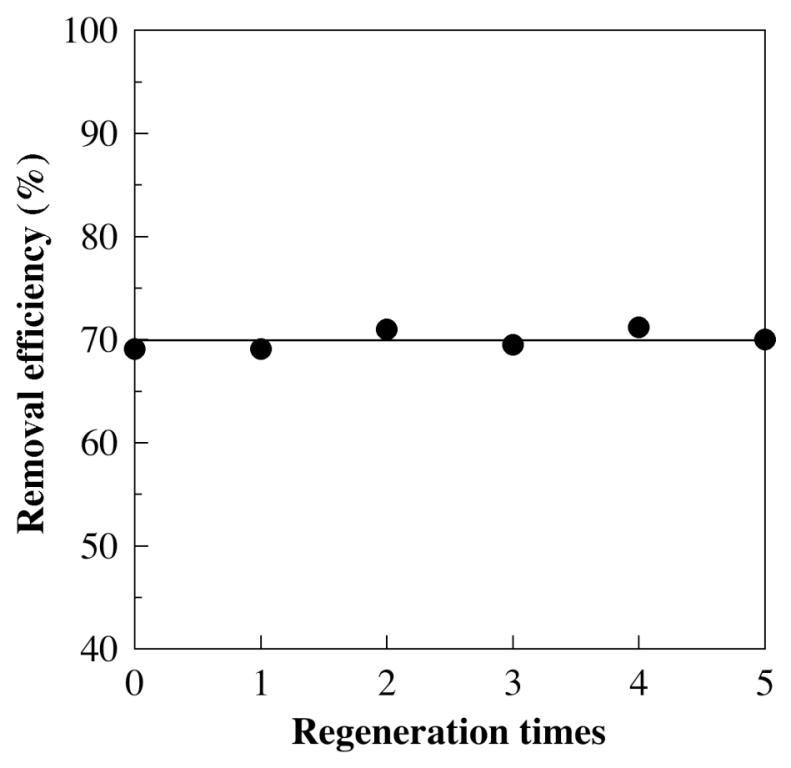

Figure 7. Removal of phenol from wastewater solution with the regenerated $[\beta-\mathrm{CyD} / \mathrm{HDI}(1 / 8)] / \mathrm{HDI}$ sorbent: Each adsorption was carried out by placing the regenerated adsorbent $(1.0 \mathrm{~g})$ and wastewater solution $\left(5 \mathrm{~cm}^{3}\right)$ in a $50-\mathrm{cm}^{3}$ Erlenmeyer flask and shaking it at $25^{\circ} \mathrm{C}$ in a chamber at $80 \mathrm{rpm}$ for 1 day. 


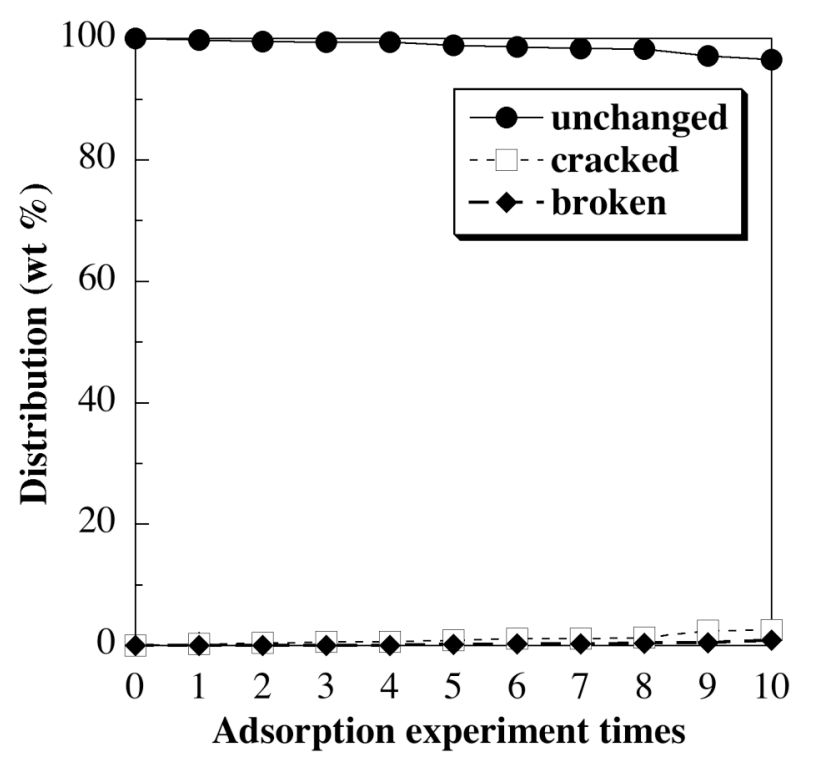

Figure 8. Mechanical stability of the $[\beta C y D / H D I(1 / 8)] / H D I$ polymer beads in batchwise adsorption. 

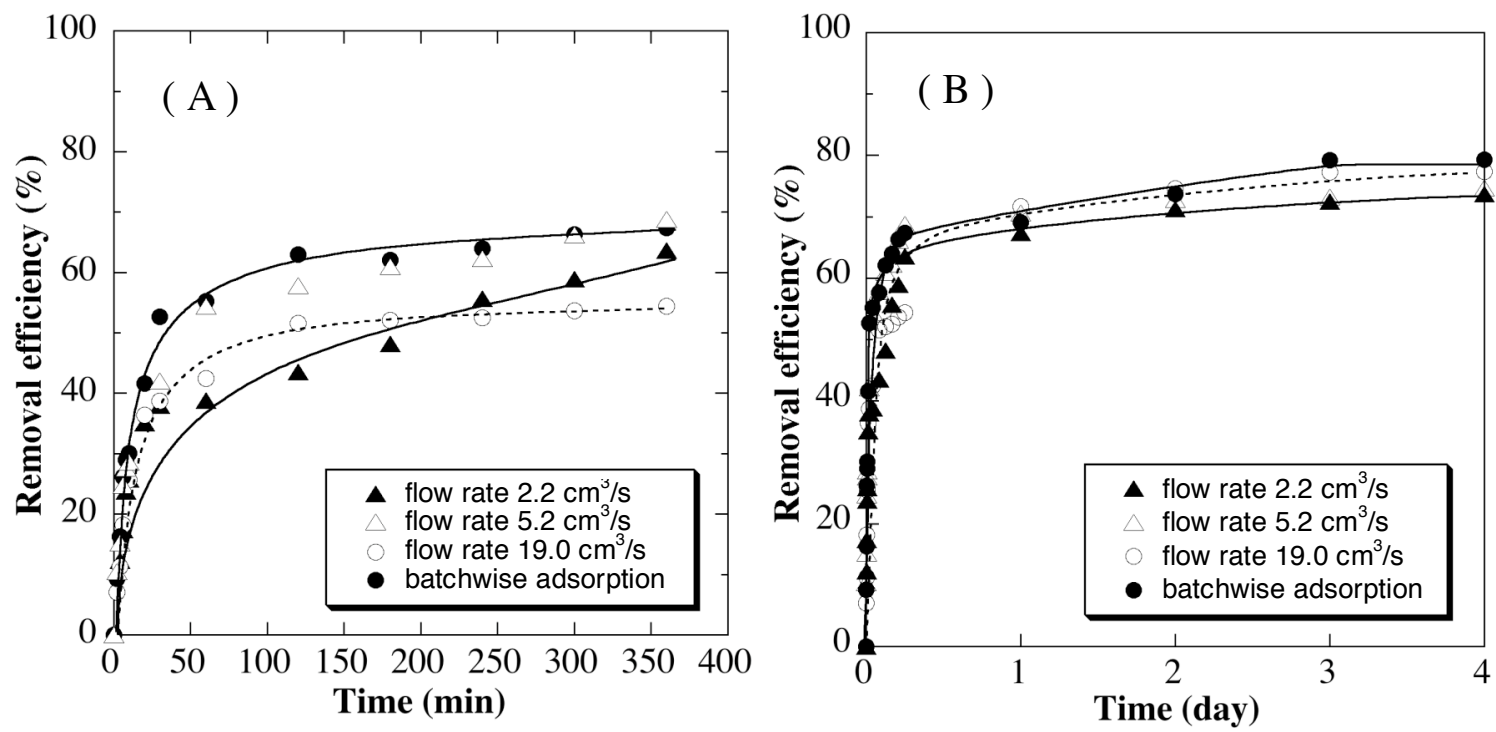

Figure 9. Efficiency of phenol removal ratio with upflow column at different circulation flow rates. (A) 6 h, (B) 4 day. 


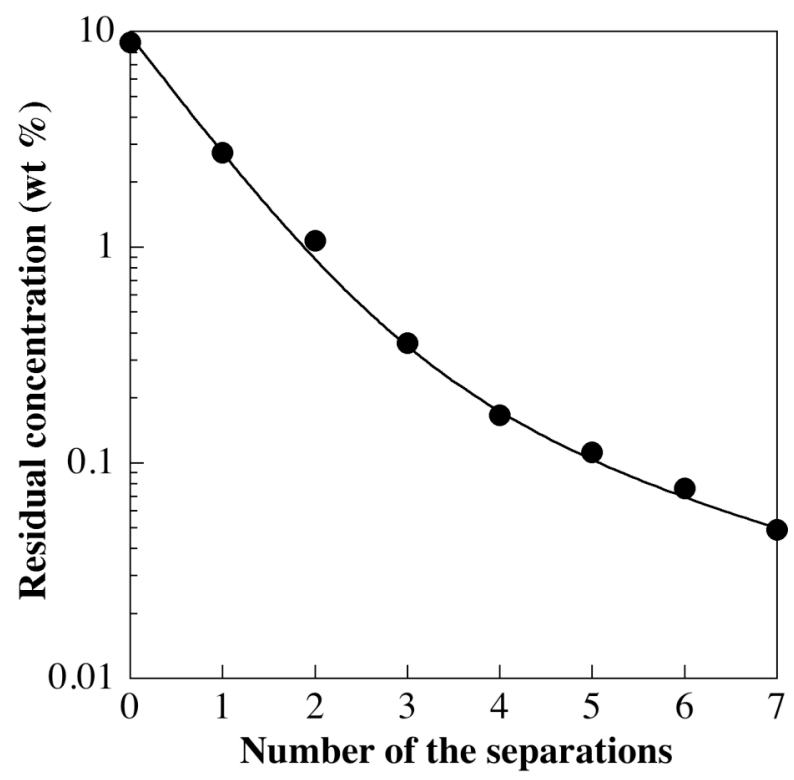

Figure 10. Repetition of the separation of phenol with the $\beta$-CyD polymer beads in an upflow column. Each adsorption was carried out by placing the regenerated adsorbent $(25 \mathrm{~g})$ and wastewater solution $\left(125 \mathrm{~cm}^{3}\right)$ in an upflow column circulating at a flow rate of $5.2 \mathrm{~cm}^{3} / \mathrm{s}$ at $25^{\circ} \mathrm{C}$ for 1 day. 